\title{
Interactive Cultural Cultivating in FLT
}

\author{
Youwen Yang \\ Beijing Foreign Studies University \\ Beijing 100089, China \\ Wenzhou University, ZheJiang 325035, China \\ E-mail: youwiny@yahoo.com.cn / youwiny@sina.com
}

\begin{abstract}
Culture cultivating in foreign language teaching (FLT) is usually conducted through factual introductions in the form of articles, books, seminars, lectures or workshops. This approach regards L2 learners as passive receivers of cultural knowledge without their interaction involved. This paper aims at raising an interactive approach to develop L2 learner's cultural awareness through contrastive analysis on data collected in an FLT classroom on the basis of observation and introspection.
\end{abstract}

Keywords: Cultural cultivating, Observation, Introspection, Contrastive analysis, FLT

\section{Introduction:}

In the 1950s and 60s, an anthropological and sociological view of language in connection with culture and society began, to a limited extent, to influence language teaching theory. Language teaching theorists began to recognize that anthropology and sociology might offer a theoretical frame-work for teaching about culture and society. They repeatedly stated that an important purpose of language learning was to learn about a country and its people. Lado, Brooks, Rivers and Chastain have all firmly stated that cultural understanding and cross-cultural comparisons are a necessary aspect of language pedagogy. In 1960 an American committee on language and culture expressed the relationships which it regarded as essential in three statements: (Bishop 1960:29)

(1)Language is a part of culture, and must be approached with the same attitudes that govern our approach to culture as a whole.

(2)Language conveys culture, so that the language teacher is also of necessity a teacher of a culture.

(3)Language is itself subject to culturally conditioned attitudes and beliefs, which cannot be ignored in language.

It is apparent that culture, as an ingrained set of behaviors and modes of perception, becomes highly important in the learning of a second language. A language is a part of a culture and a culture is a part of a language; the two are intricately interwoven so that one cannot separate the two without losing the significance of either language or culture. The acquisition of a second language, except for specialized, instrumental acquisition, is also the acquisition of a second culture. Therefore, the incorporation of culture into foreign language teaching was brought into prominence. How to develop cultural awareness on L2 learners' side has become a necessary and important ingredient and a major concern in L2 teaching and learning. Typically, a foreign culture is mainly introduced in forms of articles, books, lectures, seminars and workshops by illustrating the great varieties of customs, habits, beliefs and values. This kind of fact-based culture learning emphasizes the memorization of facts. It regards culture as something static. Language learning in this way turns out to be a knowledge transmission and passive reception learning process without L2 learners' interaction. Furthermore, realization and understanding of cultural knowledge does not necessarily result in the formation of intercultural communicative competence. Most of the time it just leads to a stereotypical comprehension of a foreign culture.

\section{Data Collection and Interactive Cultural Awareness}

Culture, as an integrated part of language, should also be taught and learned in an interactive way with learner's cognition involved. In an FLT classroom, culture learning can be incorporated into L2 learning process as a way of forming intercultural communication competence. This approach first demands authentic data collection on basis of observation and introspection.

Observation is a primary method of data collection used by anthropologists, and ultimately of great value to L2 learners as well. This approach is usually developed in three stages. First, it requires L2 learners reporting observable behaviors without imposing value judgements or drawing conclusions. Whenever there are native speakers involving in a particular conservation or event, learners attention should first be directed on 'who', 'when', 'where', 'what', 'why' and ' $h o w^{\prime}$ are involved in it. For example, in films, videos, writings, or even daily authentic social interactions, participants' 
verbal and nonverbal behaviors and social context will offer L2 learners insightful clues into the culture they are observing and learning. Normally, they are expected to keep a close eye on the following key elements in an social interaction:

a) Who is being observed? (e.g.: age, sex, role, and group membership, if more than one are involved) What is the relation between different members?

b) Where is it taking place? (e.g.: office, street, park. home, club, classroom, etc)

c) What is being done/not done? (by whom, to whom, in what manner, for what purpose, in what relation to other events) And what has been done or happened?

d) How does the event develop? (setting, beginning, developing, climax and ending)

e) How do participants react to different situations? etc.

In FLT observation can be conducted either in classroom or out of classroom with learners involved or uninvolved. The key to successful observation and inference is freeing oneself as much as possible from the restraints of one's own cultural experience. This requires cultural relativism, sensitivity and objectivity in perceiving others' culture.

Then, after L2 learners have made a factual observation, they can be directed to the second stage --- getting answers to questions. By getting answers to questions about customs, habits, beliefs and values from those behaviors observed, L2 learners are encouraged to make inferences about the many indiscernible aspects of culture. Questions to be posed could be:

a) How do people greet each other?

b) Who talks to whom in what manner on what topic?

c) Who orders whom to do what/punishes whom for what?

d) How is differencelagreement shown?

e) How is insult/praise/satisfaction/dissatisfaction/thank/apology expressed?

f) Why does whoever agree/refuse/reluctant to do what?

g) How does dress differ for age, sex, social class and social activity?

h) What behaviors are strange to you? Why? If it were you, what would you do then?

i) What is the hierarchy of authority in the family?

The last stage of observation involves the formation of L2 cultural stereotypes based upon numerous observations and answers to questions about culture L2 learners had before. They may form better outline ideas by considering the following:

a) Relations between members in office, family, campus

b) Birth, death and burials ceremonies

c) Marriage tradition and educational organization

d) Social manners and domestic manners

e) Food and cookery

f) welfare and Medical systems

g) Religions, beliefs and values of life

h) Government and its functions

i) Historical, geographical features of target language country

Of course, due to the complexity of a culture, it is rather difficult for L2 learners to form an all-in-one stereotype of the culture in question. Furthermore, inferences drawn from observation might do not agree with each other. This demands L2 learners to single out individual differences. However, this in no sense indicates that an answer to a particular question by a given individual is wrong. What L2 learners need to bear in mind all the time is the fact that there is no 'right' or 'wrong' answers--just differences. Securing information about another culture requires some degree of objectivity and openness. Anyone who does not accept the reality and validity of cultural differences as a general concept is not ready to get insight into another culture.

In FLT, observation is not simply applied for the single purpose of developing cultural awareness. It is often integrated with activities designed to develop L2 learners' communicative competence. While students are getting answers to the above questions, they are not just trying to learn the target language, but also trying to understand the target culture. In this way, the learning of a foreign culture is incorporated into foreign language teaching. 
Introspection is a means for data collection only about one's own culture. This is important not only for data collection, but also for establishing the fact that everyone has a culture. In getting to know an L2 culture (acculturation), learners are also deemed to have a clear idea what their native culture (enculturation) is. Introspection into one's native culture is just to activate an L2 learners' subconsciously embedded cultural ideas so as to develop awareness of the differences between his native and second cultures.

The first step in introspection in L2 teaching is to ask individual learners to formulate very specific answers from their own experience to various questions about culture which are imposed in the second stage in the observation process. A second stage is applying contrastive analysis to a comparison of responses to questions about culture so as to search for systematic and consistent differences between different cultures. A distinction and contrast of the two cultures in question is not only of great assistance to understanding a second culture, but also an important stage in viewing culture objectively.

\section{Contrastive Analysis of Cultural Difference and Interactive Cultural Cultivation}

Robert Lado suggests a model for contrasting aspects of culture which is quite relevant to educational purposes--'to discover and describe the problems that the speakers of one of the languages will have in learning the other.' (Lado: 1957:vii) He suggests that aspects of culture (as language) which are entirely different are less likely to cause interference and cultural misunderstanding than those which are similar on the surface but differ significantly in other ways. By contrastive analysis, L2 learners can detect three types of cultural differences which might predictably cause problems and difficulty in L2 learning and application process.

a. same form, different meaning---those very similar, or even the same, behaviors may have very different meanings in different cultures. Hissing, for example, means disapproval in the U.S., but asks for group silence in Spanish-speaking countries.

b. same meaning, different form---depending on different cultures, different behaviors are assigned with the same meaning. For example: shaking hands/head for Chinese and shrug for native English speakers are both forms of disagreement, ignorance or baffle.

c. same form, same meaning, different distribution---the same behaviors expressing the same meaning, may have culturally different contexts in which they are appropriate or inappropriate. For example, 'arm in arm' is usually a sign of close relation between members. It is appropriate between spouses, lovers or between young men and women in English countries. But in China, it is only found between man and woman as lovers, or between the same sexes as intimates, or between children and parents to show care, help, or respect to the elders from the young. (Be Jiwan, 1999:11).

The purpose of finding out these cultural differences is aiming at avoiding errors resulting from cultural differences. For example, by comparing the different language forms in greeting to each other adopted in Chinese and English separately, L2 English Chinese learners are not supposed to say "Have you eaten your dinner?" to a native speaker of English.

In comparing responses to questions about a foreign culture, three entities are involved: the teacher, the students and teaching resources (books, videos, pictures or recordings). Activities organized involving the above three will lead to three types of interaction, namely, teacher-student interaction, student-resources interaction, and student-student interaction. In the first interaction, communicative activities take place through the teacher's preliminary task assignments and a prompt and positive comment on students' answers to questions about culture. In the second interaction, communicative activities take place when students receive verbal and nonverbal messages from teaching resources (either checked or unchecked by the teacher). In the third interaction, communicative activities take place when students discuss any questions about a foreign culture or differences between the two cultures, or share information about culture with each other from their experience. Through these three kinds of interactions, students' interests and motivation are aroused. They hence become active in language learning.

\section{Conclusion}

It is self-evident that culture cultivating depends on effective interaction. Adequate input of foreign cultural knowledge in the FLT classroom seems to be of great assistance to developing cultural awareness on learner's side. In our daily L2 teaching, cultural knowledge can not only be introduced through academic approaches, such as lectures or articles, it also can be integrated with the process of developing L2 learner's communicative competence. By having learners getting answers to or organizing discussions about culture in question, and a contrastive analysis of different responses to them in different social contexts, both culture cultivating and language teaching are incorporated into a process of developing learner's communicative competence by way of developing L2 learner's cultural awareness. This is the essence of language teaching and learning from the perspective of sociolinguistics.

\section{References}

Bi Jiwan. (1999). Intercultural Nonverbal Communication. Foreign Language Teaching and Research Press. 
Bishop, G.R. (ed.) (1960). Culture in Langue Learning. Northeast Conference on the Teaching of Foreign Languages, 1960. Reports of the Working Committees. New Brunswick, N.J.: Rutgers, The State University.

Brooks, N. (1964). Language and Language Learning. $2^{\text {nd }}$ ed. New York: Harcourt, Brace and World.

Brown, H. Douglas. (1993). Principles of Language Learning and teaching. $3^{\text {rd }}$ ed. Prentice Hall Regents

Chastain, K. (1976). Developing Second-language Skills: Theory to Practice. Chicago: Rand McNally.

Kramsch, Claire. (1993), Context and Culture in Language Teaching. Oxford University Press: Shanghai.

Lado, R. (1957). Linguistics Across Cultures. Applied Linguistics for Language Teachers. Ann Arbor: University of Michigan Press.

Rivers, W.M. (1968). Teaching Foreign-Language Skills. University of Chicago Press.

Stern. H.H. (1999). Fundamental Concepts of Language Teaching. Oxford University Press: Shanghai. 